\title{
Predicting Voltage Unbalance Impacts of Plug-in Electric Vehicles Penetration in Residential Low Voltage Distribution Networks
}

\author{
Farhad Shahnia $^{1}$, Arindam Ghosh ${ }^{2}$, Gerard Ledwich $^{2}$ and Firuz Zare ${ }^{3}$ \\ ${ }^{1}$ Centre for Smart Grid and Sustainable Power Systems, Electrical and Computer Engineering Department, \\ Curtin University, Perth, Australia \\ ${ }^{2}$ School of Electrical Engineering and Computer Science, Queensland University of Technology, Brisbane, \\ Australia \\ ${ }^{3}$ Global Research and Development, Danfoss Power Electronics A/S, Graasten, Denmark \\ (Corresponding Author: farhad.shahnia@ curtin.edu.au Tel: +61-432020732)
}

\begin{abstract}
Plug-in electric vehicles (PEVs) will soon be connected to residential distribution networks in high quantities and will add to the already overburdened residential feeders. However, as the battery technology improves, PEVs will also be able to support networks as small distributed generation units by transferring the energy stored in their battery into grid. Even though the increase in the PEV connection is gradual, their connection points and charging/discharging levels are random. Therefore, such single-phase bi-directional power flow can have adverse effect on the voltage unbalance of a three-phase distribution network. In this paper, a voltage unbalance sensitivity analysis based on charging/discharging levels and the connection point of PEVs in a residential low voltage distribution network is presented. Due to many uncertainties in PEVs ratings and connection points and the network load, a Monte Carlo based stochastic analysis is developed to predict the voltage unbalance in the network in the presence of PEVs. A failure index is introduced to demonstrate the probability of non-standard voltage unbalance in the network due to PEVs.

Keywords-Distribution Network, Plug-in Electric Vehicle, Sensitivity Analysis, Stochastic Analysis, Voltage Unbalance
\end{abstract}




\section{INTRODUCTION}

The technical developments in automotive sector along with environmental concerns and fuel prices have lead to appearance of Plug-in Electric vehicles (PEV). In [1], it was estimated that PEVs market penetration will be about 1.5 million in 2016 and over 50 million in 2030 (almost 25\% of all new car purchases). It was also stated that PEVs penetration into market will result in annual $2 \%$ increase in network load growth which is twice of air conditioning loads.

The PEVs will be charged by drawing current from the network as owners return home in the evening/night (immediately or with a delay when considering the off-peak tariff possibility) until they are fully charged or they depart. This will lead to an increase in the number of single-phase loads in the network considerably. The charging of PEVs is often referred to as Grid-to-Vehicle (G2V) operation mode. However, in close future and with battery technology improvement, it is expected the PEV battery can inject its stored energy back into the grid, too. In this mode, often referred to as Vehicle-to-Grid (V2G), PEVs can be used as temporary local dispersed generation units when parked at home during the day. This means that PEVs can be assumed as loads or generators in the network [2-3].

PEVs are a significant load for future residential distribution networks, especially when high clusters of PEVs are in a certain area. They can be charged in two general locations: individual charging points (in residential and small business places) and charging stations. Rapid charging (in less than one hour) is expected in charging stations which are being fed from three-phase networks. However, normal charging (in 6-8 hours) from single-phase LV outlets is expected in individual charging points [4].

PEV characteristics can impose technical problems to the network and require an expansion or modification to network structure, policies, control and protection. The effects of PEVs penetration on voltage drop, power loss and costs in distribution networks is studied in [3-8] through deterministic or probabilistic methods. In [9-12], the authors have carried out a general study of power quality issues of the distribution network due to PEVs integration and have utilized controlled charging for reducing the power quality problems. 
Voltage unbalance (VU) is one of the major power quality problems in low voltage (LV) distribution networks [13]. Electric utilities try to distribute the residential loads equally among the three phases of distribution feeders. Although voltages are well balanced at the supply side level, the voltages at the customer level can become unbalanced due to the unequal system impedances, unequal distribution of single-phase loads or large single-phase loads.

PEVs can increase network VU since they are relatively huge single-phase load/generator units. Although VU due to PEVs was discussed in [9-12], but it was not studied exclusively. The effect of charging/discharging levels and location of PEVs were not considered in these studies. The V2G and $\mathrm{G} 2 \mathrm{~V}$ operation modes were not also investigated thoroughly for VU analysis. Investigating VU due to PEVs in the network is the main contribution of this paper. This investigation is of high interest since the random connection point of PEVs among the three phases of the LV residential network in addition to their charging levels, in G2V mode and their output power, in V2G mode, might increase network VU.

Therefore, in this paper, first a VU sensitivity analysis is carried out vis-à-vis the location and charging/discharging levels of PEVs in LV residential networks. This analysis will demonstrate network VU relation with charging/discharging levels of PEVs in addition to their location along the feeder in different phases. This analysis is later followed to investigate network VU due to several PEVs in the network.

A deterministic analysis may not be suitable due to the randomness in PEVs penetration level, capacity and connection points in addition to the residential loads variations. Therefore, a stochastic analysis based on Monte Carlo method [14-15] is later carried out in this paper to investigate and predict the network VU for the uncertainties arising due to PEVs and network loads. Based on the developed stochastic analysis tool, the efficacy of some of the conventional improvement methods in VU reduction is verified in MATLAB. 


\section{Voltage Unbalance}

VU in three-phase systems is a condition in which the three phase voltages differ in magnitude and/or do not have normal 120 degree phase differences. References [16-19] have investigated different VU measurement and calculation methods based on line or phase voltages in three-phase, three and four wire systems. However, based on IEEE Recommended Practice for Monitoring Electric Power Quality [19], VU is calculated as

$V U \%=\left|\frac{V_{-}}{V_{+}}\right| \times 100$

where $V_{-}$and $V_{+}$are the negative and positive sequences of the line voltage, respectively. According to [19], the allowable limit for VU is limited to $2 \%$ in LV networks. Engineering Recommendation P29 in UK not only limits VU of the network to $2 \%$, but also limits the VU to $1.3 \%$ at the load point [20]. In this paper, we assume $2 \%$ as the standard limit.

References [19-20] indicate that VU is to be calculated from network line voltages in 10 minute time intervals where only the data with confidence level of $95 \%$ are to be used in this calculation. This time and confidence level based calculation method is to remove the load transient and intermittency effects from VU calculation since VU in general represents the steady-state condition of the network.

\section{Network Modeling and Analysis}

A typical radial LV residential urban distribution feeder is considered in this paper, with the single line diagram shown in Fig. 1a. For analyzing this network, the neutral conductor that creates a path for the return current is taken into consideration and the analysis is based on the mutual effect of the three phases. It is to be noted that since IEEE standard test feeders are generally designed for medium voltage distribution and transmission networks, the network of Fig. 1a is used in this study which has a better representation of a typical LV network.

As discussed in Section II, since VU is in general a steady-state parameter of the network and is be measured at 10 minute time intervals, the transient and intermittent characteristic of PEVs and loads are not of interest in VU studies and are not considered in the reset of this research. Thereupon, the PEVs are assumed as constant current load in G2V mode and for V2G mode, they are assumed to be 
battery storage devices with constant output power. The schematic diagrams of the PEV in these two modes are shown in Figs. 1b \& 1c.

\section{A. Load Flow Analysis}

For calculating the VU, it is necessary that the network to be analysed and the voltages at the desired nodes to be calculated. Based on Kirchhoff Current Law (KCL) on the $k^{\text {th }}$ node of phase $A$, we have

$\beta_{1} \cdot I_{A, P E V, k}+\frac{\beta_{2}\left(V_{A, P E V, k}-V_{A, k}\right)}{X_{A, P E V, k}}+\frac{V_{A, k-1}-V_{A, k}}{Z_{f}}+\frac{V_{A, k+1}-V_{A, k}}{Z_{f}}+\frac{V_{N, k}-V_{A, k}}{Z_{A, L, k}}=0$

where $Z_{f}$ is the feeder impedance between two adjacent nodes in phase lines, $V_{A, i,}(i=1, \ldots, n)$ is the single-phase voltage of the $i^{\text {th }}$ node of phase $A, Z_{A, L, k}$ is the load impedance connected to $k^{\text {th }}$ node of phase $A$ and $V_{N, k}$ is the voltage of the neutral wire connected to $k^{\text {th }}$ node. In (2), $\beta_{1}=-1$ when a PEV, running in $\mathrm{G} 2 \mathrm{~V}$ mode, is connected to $k^{\text {th }}$ node of phase $A$, otherwise, it is zero. Also, $\beta_{2}=+1$ when a $\mathrm{PEV}$, running in $\mathrm{V} 2 \mathrm{G}$ mode, is connected to $k^{\text {th }}$ node of phase $A$, otherwise, it is zero. In G2V mode, $I_{A, P E V, k}$ is the charging level of the PEV connected to that node. In V2G mode, $V_{A, P E V, k}$ and $X_{A, P E V, k}$ are the PEV converter output voltage and impedance connected to that node. Similar KCL equations will be considered for phases $B$ and $C$ and the neutral wire.

From Fig. 1c, for PEV in V2G mode, we have

$$
\begin{aligned}
& P_{P E V, k}=\frac{\left|V_{P E V, k}\right|\left|V_{k}\right|}{X_{P E V, k}} \sin \left(\delta_{P E V, k}-\delta_{k}\right) \\
& Q_{P E V, k}=\frac{\left|V_{k}\right|}{X_{P E V, k}}\left(\left|V_{P E V, k}\right| \cos \left(\delta_{P E V, k}-\delta_{k}\right)-\left|V_{k}\right|\right)
\end{aligned}
$$

where $P_{P E V, k}$ and $Q_{P E V, k}$ are respectively the active and reactive power output of the PEV connected to $k^{\text {th }}$ node. Assuming $P_{P E V, k}$ and $Q_{P E V, k}$ to be constant and $\left|V_{k}\right|$ and $\delta_{k}$ are known, $\left|V_{P E V, k}\right|$ and $\delta_{P E V, k}$ can be calculated. In this analysis, it is assumed that $Q_{P E V, k}=0$ and PEV only injects active power into grid.

To calculate $V_{k}$ from (2)-(4), a sweep forward-backward based iterative method [21-22] is used to perform the load flow analysis in the considered radial network of Fig. 1a. For this, starting with a set of initial values, the entire network is solved to determine $V_{k}$. Once the solution converges, the 
sequence components are calculated. These sequence components are later used for VU calculation as in (1).

\section{B. Sensitivity Analysis}

The voltage at any node can be considered as a function of PEV location and charging/discharging capacity. Using the load flow method described above, the voltages at each node are calculated iteratively. Once the iterations converge, the voltage unbalance sensitivity is calculated numerically as

$S_{k}=\alpha \cdot \frac{V U(\gamma+1)-V U(\gamma)}{I_{P E V, k}(\gamma+1)-I_{P E V, k}(\gamma)}+(1-\alpha) \frac{V U(\gamma+1)-V U(\gamma)}{P_{P E V, k}(\gamma+1)-P_{P E V, k}(\gamma)}$

where $\alpha=1$ for the analysis in G2V mode and is equal to zero for the analysis in V2G mode. In (5), $\gamma$ defines the charging and discharging capacity of PEV. For G2V mode, $0 \leq \gamma \leq 2$ represents the three charging levels of 10, 15 and 20 A. For V2G mode, $0 \leq \gamma \leq 4$ represents the output active power of PEVs (i.e. 1, 2, 3, 4, $5 \mathrm{~kW}$ ).

\section{Stochastic Analysis}

The load demand in residential distribution networks varies within the 24-hour daily time period. This variation is random and different for all the customers in the network. In addition, it is expected that the PEV power consumption or generation levels to be different for different owners. In addition to these issues, random connection points of PEVs, their nominal charging/discharging capacities, their operation durations and different driving patterns of owners increase the uncertainties in the network.

For investigating the uncertainty effects on the network VU, a Monte Carlo based stochastic analysis is carried out. The considered uncertainties in this research are: PEV penetration level, charging and discharging capacity, connection points along the feeder on all phases and the residential load demand. The flowchart of the Monte Carlo method used in this study is shown in Fig. 2.

It is to be noted that driving pattern can be another parameter to be considered when investigating medium voltage distribution network which supplies the loads in a large area. Driving pattern generally demonstrates the location in which PEVs are parked during the 24-hr period (i.e. home, parking lot, store/shopping center parking, employer's parking) and the parking duration [2]. This 
parking location and duration is to be used for determining where and how long the PEVs are in charge/discharge mode at different time of the day. The higher the number of PEVs parked in an area, the higher probability of power quality problems such as non-standard VU in the feeder supplying them. However, this parameter is not considered in the stochastic analysis in this paper as this paper focuses only on one LV residential network.

For reducing and eliminating the non-desired combinations of the input parameters for the stochastic analysis, a Time parameter is considered which represents the time of the analysis over the 24-hr period and is normalized in [0 1] range. Time is utilised to select correlated random numbers among load demand and as well as the operation mode (i.e. G2V and V2G) of PEVs while the PEV number and location parameters are considered independent from the Time Parameter.

The study is carried out for G2V and V2G modes separately. In this study, first it is assumed the PEVs have equal probability of $33 \%$ each for 10,15 and 20 A charging levels in G2V mode. Therefore, for selecting 1 out of these 3 charging levels, a random number $U_{l}$ distributed uniformly under $[0,1]$ is used. If $U_{l}<0.33$ then $10 \mathrm{~A}$ charging level is selected, if $0.33 \leq U_{l} \leq 0.66$ then $15 \mathrm{~A}$ charging level is selected and if $U_{l}>0.66$ then 20 A charging level is selected. However, there might be some cases in which the PEVs in an area all have same charging levels. Therefore, later in the paper, some analyses are carried out assuming a normal distribution of the charging levels to investigate such scenarios.

For V2G mode, it is assumed that PEVs have equal probability of $20 \%$ each for $1,2,3,4$ and $5 \mathrm{~kW}$ output active power being fed into grid. As mentioned earlier, this will be the scenario in the future distribution networks where a central controller will control the output power of the PEVs in V2G mode. In such a scenario, it is probable that PEVs within a network to have different discharge level due to the network electrical parameters which are monitored and controlled by the smart grid central controller. That is why a uniform distribution of PEVs discharging levels is considered in this study. Similar to G2V mode, the random number $U_{l}$ distributed uniformly under $[0,1]$ is used for selecting the PEVs discharging level in this mode. Therefore, it is assumed that

$$
\begin{aligned}
& \text { if } U_{l}<0.2 \quad \text { then } P_{P E V, k}=1 \mathrm{~kW} \\
& \text { if } 0.2 \leq U_{l}<0.4 \text { then } P_{P E V, k}=2 \mathrm{~kW}
\end{aligned}
$$




$$
\begin{aligned}
& \text { if } 0.4 \leq U_{l}<0.6 \text { then } P_{P E V, k}=3 \mathrm{~kW} \\
& \text { if } 0.6 \leq U_{l}<0.8 \text { then } P_{P E V, k}=4 \mathrm{~kW} \\
& \text { if } U_{l} \geq 0.8 \quad \text { then } P_{P E V, k}=5 \mathrm{~kW}
\end{aligned}
$$

However, later in the paper, some cases are also considered with normal distribution of discharge levels for the PEVs to investigate the effect of such cases.

The network load demand is chosen by random number $U_{2}$ which is defined from the Time parameter. A bottom-up residential load demand modelling was developed in [23] where each residential electric appliance was modelled in detail. A normal distribution function with a selected average and variance was used to define the electric power consumption of each appliance. In addition, a similar normal distribution was utilized to define the operation starting time of each electric appliance, operation duration and frequency of operation of each device in each house separately. The total load demand of a house was later calculated by adding all the electric power consumptions of the appliances in that house in that time of the day. In this paper, the data of the developed residential load modelling in [23] is utilised to define the electric power consumption of each house at that specific time of the day based on the Time Parameter. The total load demand of each house is within the range of $[0,5 \mathrm{~kW}]$.

The number of PEVs in a network is selected based on the penetration levels of PEV for different short-term and long-term periods. This value is chosen by a random number $U_{3}$ which has a normal distribution of $\mathrm{N}(\mu, \sigma)$ with mean value of $\mu=$ penetration level [\%] $\times$ number of householders in the feeder and variance of $\sigma=0.02$.

The uncertainty of PEV location along the feeder (i.e. $[0,400 \mathrm{~m}]$ in this study) is modelled by drawing a random number $U_{4}$ distributed uniformly under $[0,1]$. This is carried out for all 3 phases and 3 feeders of the studied network independently.

The average $\mathrm{VU}\left(\overline{V U_{j}}\right)$ from Monte Carlo trials $1 \leq k \leq N$, is calculated at the studied nodes (i.e. beginning or end of feeder) by

$\overline{V U_{j}}=\frac{1}{N} \sum_{k=1}^{N} V U_{k}$ 
The standard deviation (STD) of VU at the studied nodes (i.e. beginning or end of feeder) is also calculated as

$$
\operatorname{STD}\left(V U_{j}\right)=\sqrt{\frac{1}{N-1} \sum_{k=1}^{N}\left(V U_{k}-\overline{V U}_{j}\right)^{2}}
$$

The stopping rule of the Monte Carlo method is chosen based on achieving an acceptable convergence for $\overline{V U}$ and $\operatorname{STD}\left(V U_{j}\right)$. For this, the Monte Carlo simulation is deemed to have converged when a confidence degree of $95 \%$ is achieved. However, a minimum of $N=10,000$ trials was also utilized to avoid premature convergence.

It is to be noted that Monte Carlo simulation might have a huge computational complexity depending on the problem it is used for. The computation efficacy can be significantly improved by developing a better simulation algorithm to minimize execution time and the unrequired storage data [14-15]. Further computation efficacy can be achieved if the desired value in the output of a Monte Carlo method is achieved in fewer trials while fulfilling the desired confidence level. For this, a proper variance reduction method is required. In this research, as the simulation time was reasonable and the results could fulfil the desired confidence level, no variance reduction method was utilised.

The VU results as the output of the Monte Carlo simulations are used to calculate the Probability Density Function (PDF) and the average (mean value) of all VUs which is shown as $\lambda$ in the paper.

\section{Numerical Results}

Let us assume one $11 \mathrm{kV}$ overhead line is feeding several $11 \mathrm{kV} / 400 \mathrm{~V}$ distribution transformers. One distribution transformer is selected for the rest of the study and the other transformers are modelled as a lumped load of the $11 \mathrm{kV}$ network. It is assumed that the total electric demand of the $11 \mathrm{kV}$ network is 1 MVA. The distribution transformer studied is assumed to have a demand of $360 \mathrm{~kW}$. The studied transformer has three feeders, each three-phase, with equal length of $400 \mathrm{~m}$ and equal number of customers on each phase. The poles are located at a distance of almost 40 meters from each other. At each pole, 2 houses are supplied from each phase. The feeder cross-sections are designed 
appropriately based on nominal power and voltage drop. The network technical data is given in Table VIII in the Appendix.

As discussed in Section III(C), a bottom-up residential load modelling was developed in [23] for all different types of residential electrical appliances including PEVs. The data of PEVs developed in [23] is utilised in this paper where each PEV has a random starting time generated by normal distribution functions. This starting time represents the time when the customers arrive home. The PEVs are in charging mode, until the battery is fully charged or the customer departs (whichever occurs first). The PEVs are assumed to have a constant charging level (from Australian standard 10, 15 and $20 \mathrm{~A}$ residential outlets) in G2V mode. They also have a constant output power (of $1-5 \mathrm{~kW}$ ) in V2G mode when parked at home during the day. The charging/discharging levels have the distributions as described in Section III(C) [7]. Average driving distance of $50 \mathrm{~km} /$ day with an economy of 20 $\mathrm{kWh} / 100 \mathrm{~km}$, charge/discharge efficiency of $90 \%$ and minimum state of charge of $20 \%$ for the PEV batteries along with the selected charging/discharging level were considered in calculating the operation duration of PEVs in G2V and V2G modes. It is to be noted that, a more accurate and detailed modelling of PEVs can be carried out using the historical data from driving surveys and traffic data. However, as discussed in [1-2], instead of the historical traffic data, the average driving distance is used in this research to calculate the energy depletion of a PEV battery after daily driving. More details on the PEVs modelling are given in [23].

In this study, a 10 and $30 \%$ penetration level of PEVs for short-term and 50\% penetration level for long-term is considered [4-5]. It is to be noted that even in the case of short-term small penetration level, high localized concentrations of PEVs are possible.

Let us assume that during the period of study, the loads of phases $A, B$ and $C$ are 60,120 and 180 $\mathrm{kW}$, respectively. In the network under consideration, the voltage amplitude at the beginning of the feeder is $0.98,0.97$ and 0.96 pu for phases $A, B$ and $C$, respectively. These values decrease to 0.95 , 0.93 and $0.90 \mathrm{pu}$ at the end of the feeder, respectively. Therefore, VU at the beginning of the feeder has increased from 0.88 to $1.84 \%$ at the end. In the rest of this paper, VU is always monitored at the feeder end nodes as these nodes have a higher probability of observing non-standard VU. 
Several studies are performed, some of which discussed below. These studies are carried out for G2V and V2G modes in two separate scenarios as their timings are different.

\section{A. Sensitivity analysis of a single PEV on $V U$}

The VU profile variation in a feeder as the result of one PEV connection will depend on the total load of the phase in which it is connected, PEV's operation mode and the point at which it is connected.

In $\mathrm{G} 2 \mathrm{~V}$ mode, it is expected that the voltage amplitude and profile will be reduced in the phase which the PEV is connected to. Let us consider a PEV with 10 A and 20 A charging levels is connected to the beginning and end of a feeder. In Fig. 3a, the voltage profile of phase $A$ is shown. As expected, the voltage amplitude decreases when the PEV is connected and the impact is more when it is connected at the end of the feeder and when its charging level is higher.

In G2V mode, the connection of a PEV in a low load phase (phase $A$ in this case) results in the reduction in voltage difference and hence $\mathrm{VU}$ at the end of the feeder decreases while having minor effect at the beginning of the feeder. This VU reduction is more if PEV is connected to the far end nodes of the feeder or if the charging level of PEV is higher. The sensitivity analysis of VU (calculated at the end of the feeder), versus the location and charging level of one PEV in G2V mode, connected to low load phase $A$, is shown in Fig. $3 \mathrm{~b}$.

For V2G mode, it is expected that the voltage amplitude and profile will be increased in the phase which the PEV is connected to. Therefore a PEV running in V2G mode, when connected to a low load phase, will result in increasing the VU. Again, the impact is more when the PEV output power is higher or when it is connected to the far end nodes of the feeder. The sensitivity analysis of VU (calculated at the end of the feeder), versus the location and output power of one PEV in V2G mode, connected to low load phase $A$, is shown in Fig. 3c.

In the above-mentioned study cases, the VU of $1.84 \%$ in the case of no PEVs increases to $1.96 \%$ (i.e. a $6.3 \%$ rise) when a PEV with charging level of $20 \mathrm{~A}$ is connected to the low load phase at the end of feeder. The VU of $1.96 \%$ at the end of the feeder is not significant since it still is within the standard limit. However, this may not be true when more than one PEV is connected to the network. 
Similarly, it can be shown that when the PEV is connected to highly loaded phase (phase $C$ ), in G2V mode, the voltage difference between the phases increases. This increase is more if the PEV is connected to the far end nodes of the feeder or if it has a higher charging level. However, in V2G mode, the voltage difference between the phases decreases. This decrease is more if the PEV is connected to the far end nodes of the feeder or if it has a higher output power.

\section{B. Sensitivity analysis of multiple PEV on VU}

In this part, it is assumed that several PEVs are connected to only one phase of the network. Note that there are three feeders and the PEVs will be connected to only the low load phase $(A)$ in each of these feeders.

Figs. $4 \mathrm{a} \& 4 \mathrm{~b}$ show the VU in Feeder-1 at the beginning and end of the feeder for V2G and G2V modes, separately. We first add PEVs to phase $A$ of Feeder-1, one at a time with the maximum number being 10. Then the PEVs are added to phase $A$ of other two feeders in the same manner. During this, the charging/discharging capacity of the PEVs (i.e. charging level of 10, 15 and $20 \mathrm{~A}$ in G2V mode and constant output power of 1, 2, 3, 4 and $5 \mathrm{~kW}$ in $\mathrm{V} 2 \mathrm{G}$ mode), is assumed to be the same.

Form Fig. 4a, it can be seen that VU in Feeder-1 rises rapidly as the PEVs working in V2G mode are added. However, adding PEVs in the other two feeders does not cause a significant increase in the VU in Feeder-1. Also it can be seen that VU increases with the output power of the PEVs. Moreover, note that VU at the beginning of the feeder does not change much.

Fig. $4 \mathrm{~b}$ shows that VU in Feeder-1 decreases as the PEVs working in G2V mode are added. Also it shows that VU decreases more if the charging level of PEVs is higher. Similar to V2G mode, VU at the beginning of the feeder does not change much.

The same study is carried out for highly loaded phase $(C)$ and the results are shown in Fig. $4 \mathrm{c} \& 4 \mathrm{~d}$. Form Fig. 4c, it can be seen that VU in Feeder-1 decreases rapidly as the PEVs working in V2G mode are added. However, adding PEVs in the other two feeders will lead to an increase in voltage profile of phase $C$ and after a point, the VU will start to increase. This increase is more obvious for PEVs with 
higher output power (i.e. 4 and $5 \mathrm{~kW}$ PEVs). However, the VU at the beginning of the feeder decreases slightly while all the PEVs are being added.

Fig. $4 d$ shows that VU in Feeder-1 decreases very slightly to a point as the PEVs working in G2V mode are added in Feeder-1. After a point, the number of PEVs and their load is highly increased and this results in a reduction in the voltage profile of Phase $C$. This leads to an increase in VU at the end of the network, while a slight variation is reflected at the beginning of the feeder.

Another study is performed to find out the effects of number of PEVs connected to one phase on $\mathrm{VU}$, while their total power consumption (in G2V mode) or power injection (in V2G mode) remains constant. This study is carried out for either at $10 \mathrm{~kW}$ or $20 \mathrm{~kW}$ total power injection in V2G mode and total power consumption of $100 \mathrm{~A}$ in G2V mode, when the PEVs are connected to low load phase A. The numerical results are shown in Table I and II for V2G and G2V modes, respectively. The results highlight the importance of the location of PEV connection on VU.

For example, if $2 \times 5 \mathrm{~kW}$ PEVs in V2G mode are connected to nodes 1,10 or 2, 10 or 5, 10 of phase $A$, they will result in different values of VU. Now, if the PEVs are chosen $5 \times 2 \mathrm{~kW}$, the VU might have increased or decreased compared to the previous situation. Therefore, making a general conclusion about VU for different numbers of PEVs in V2G mode on one phase but with constant total injected power seems to be impossible without taking into account their locations. Hence, from Table I, it can be concluded that the VU is greater if PEVs with constant total power injection are installed at the end of the feeder comparing to when installed at the beginning. Similar discussion can be carried out for PEVs in G2V mode. In this case, it can be concluded that VU is greater if PEVs with higher charging levels are connected to the end of the feeder comparing to when installed at the beginning.

\section{Stochastic Analysis of VU}

A stochastic analysis is carried out for investigating the uncertainties in the network based on the explanation in Section III. A sample result for VU calculated at the beginning and the end of the feeder for a $30 \%$ penetration level of PEVs working in G2V mode is shown in Fig. 5a. From this figure, it can be seen that $\mathrm{VU}$ calculated at the beginning of the feeder always remain less than $1.2 \%$. However, VU at the end of the feeder varies between $1.2 \%$ and $2.6 \%$. The PDF of VU for the $30 \%$ 
penetration level of PEVs in G2V mode is shown in Fig. 5b. In this case, $\lambda=0.95 \%$ at the beginning of the feeder and $\lambda=1.89 \%$ at the end of the feeder.

From Fig. 5b, it can be seen that, there is a high probability that the VU at the end of the feeder to be more than the $2 \%$ standard limit. This probability, which shows the frequency of the cases in the shaded area, is referred to as the Failure Index and is calculated by $F_{I} \%=$ Shaded Area $\times 100$. While $F_{I}$ of $\mathrm{VU}$ is zero at the beginning of the feeder, it is about $34.1 \%$ at the end of the feeder.

This study is carried out for different penetration levels of PEVs in both G2V and V2G modes. The $\lambda$ at the beginning and end of the feeder and $F_{I}$ results of this study is given in Table III. From the data in Table III, it can be seen that as the PEV penetration level increases from 0 to $50 \%$, the probability of non-standard $\mathrm{VU}$ at the end of the feeder increases from 0 to $36.5 \%$ for $\mathrm{G} 2 \mathrm{~V}$ mode and from 0 to $28 \%$ for $\mathrm{V} 2 \mathrm{G}$ mode.

The customer load consumption is time variant. It is expected that in some periods of the day, the loads in three phases of the network are highly unbalanced or to be almost balanced. Therefore, the residential loads also have an effect on the VU. This phenomenon is included as the fourth uncertainty condition for Monte Carlo method. The results of this analysis are given in Table IV for different load consumption levels in the network assuming a constant level of $30 \%$ for PEV penetration. It can be seen that when the loads are almost balanced, $\lambda$ and $F_{I}$ decrease while they increase if the loads are highly unbalanced in the network.

In Section III(B), the connection effect of a single PEV on VU, when connected to beginning or end of a feeder, was demonstrated through the sensitivity analysis. In the previous stochastic studies, it was assumed the PEVs were distributed randomly along the feeder with a uniform distribution as discussed in Section III(C). However, there might be scenarios where majority of the PEVs are connected to the beginning or to the end of a feeder. For this, another Monte Carlo study is carried out where a normal distribution of PEVs connection points along the feeder is utilised instead of the previous uniform distribution. The normal distribution function is adjusted such that three different scenarios with majority of PEVs connections points in beginning, middle and end of the feeder are populated for a $30 \%$ penetration level of PEVs. The results of this study are given in Table V. From this table, it can be seen that when majority of PEVs are connected to end nodes of the feeder, the failure index is 
relatively large (i.e. $54.6 \%$ in $\mathrm{V} 2 \mathrm{G}$ mode and $32 \%$ in $\mathrm{G} 2 \mathrm{~V}$ mode) compared to when majority of PEVs are connected to the feeder beginning nodes where this figure is relatively small (i.e. $5.5 \%$ in V2G mode and $12.2 \%$ in $\mathrm{G} 2 \mathrm{~V}$ mode).

In all previous study cases, it was assumed that charge and discharge capacities of PEVs have a uniform distribution. However, it is also possible that majority of the PEVs in a network, at any specific time, operate with a similar charge or discharge capacity. For analysing such cases, another case study is carried out where the uniform distribution of charge/discharge capacities is replaced with a normal distribution on each level of charge/discharge capacity of PEVs in the network. The results of this analysis, for a $30 \%$ penetration level of PEVs, are given in Table VI. From this table, it can be seen that when majority of PEVs operate in higher charge/discharge levels, $\lambda$ is left constant; however, $F_{I}$ increases gradually from 31.3 to $38.3 \%$ in G2V mode and from 14.9 to $30.1 \%$ in V2G mode as the charge/discharge capacity is increased from 10 to $20 \mathrm{~A}$ in $\mathrm{G} 2 \mathrm{~V}$ and from 1 to5 $\mathrm{kW}$ in V2G modes, respectively.

\section{IMPROVEMENT METHODS}

Based on the numerical and stochastic results of Section IV, it can be concluded that for the network under consideration, $\mathrm{VU}$ at the beginning of the feeder, regardless of the location, number and charging/discharging capacity of the connected PEVs, is likely to be less than $1.2 \%$. However, the VU at the end of the feeder can be more than $2 \%$ standard limit for $34.1 \%$ of the cases. Therefore, investigating the VU reduction methods seems to be essential.

The VU reduction methods can be divided into longer-term and shorter-term improvement methods. The most effective method of VU reduction due to PEVs effects is utilising a centralised coordinated operation of PEVs $[7,9,24]$. In this method, a central controller within the network can be developed such that it optimises the operation time and level of PEVs within the network for voltage profile improvement. Another effective VU reduction method is developing a decentralised coordinated operation for PEVs using minimal communications and the local controller installed at each PEV [25]. In [25], it was shown that the PEVs operation can be coordinated such that the VU is minimised to zero in real-time. Although these methods can utilise optimisation techniques, load 
forecasting and electricity market data; they are based on the availability of central or local controllers in the network, smart meters, communication facilities, etc. which are costly and can be considered in the longer-term planning of the distribution networks.

For the short-term planning of the network, the following five VU reduction methods can be considered [26-28] where the efficacy of these methods are studied and discussed below:

(1) Increasing feeder cross-section: This will result in reducing the voltage drop along the feeder and therefore, there will be little difference among the voltage amplitude of three phases of a feeder at the end.

(2) Installing capacitors: Installation of pad mounted switched capacitors in the LV feeders. It is important to note that if a three-phase capacitor is installed on a LV feeder, the voltage unbalance will almost remain the same. However, if a capacitor is connected only on a phase at a point where the voltage is below $0.95 \mathrm{pu}$, the voltage profile of the phase can be improved.

(3) Both feeder cross section increase and capacitor installation: This is a combination of the above two methods.

(4) DSTATCOM Installing: Shunt installation of a DSTATCOM at $2 / 3^{\text {rd }}$ distance from feeder beginning.

(5) DVR Installing: Series Installation of a DVR with the LV feeder at $1 / 3^{\text {rd }}$ of feeder beginning.

To verify the efficacy of these methods, another set of stochastic studies are carried out assuming a $30 \%$ penetration level for PEVs and the results are given in Table VII. In this, the nominal case indicates when the feeder cross-section is $70 \mathrm{~mm}^{2}$ and no capacitors are installed in the system. For method (1) mentioned above, the feeder cross-section is increased to $95 \mathrm{~mm}^{2}$. In this case, the $F_{I}$ reduces to 34.1 to $7.7 \%$ in $\mathrm{G} 2 \mathrm{~V}$ mode and from 26 to $0.5 \%$ in V2G mode. For method (2), a $15 \mathrm{kVAr}$ capacitor is installed at the $2 / 3^{\text {rd }}$ distance from the beginning of the feeder. In this case, the $F_{I}$ reduces to $0.4 \%$ in $\mathrm{G} 2 \mathrm{~V}$ mode and to zero in $\mathrm{V} 2 \mathrm{G}$ mode. For method (3), feeder cross-section has been increased to $95 \mathrm{~mm}^{2}$ and a $15 \mathrm{kVAr}$ capacitor is installed at the $2 / 3^{\text {rd }}$ distance from the beginning of the feeder. In this case, the $F_{I}$ is zero in both modes. For method (4), a $15 \mathrm{kVA}$ DSTATCOM is connected in parallel to the $2 / 3^{\text {rd }}$ distance of feeder beginning. The DSTATCOM is intended to fix the 
voltage of its point of common coupling to a desired value of 0.98 pu by injecting a required amount of reactive power. In this method, the $F_{I}$ reduces to zero in both modes. For method (5), a $3 \mathrm{kVA}$ DVR is connected in series to the $1 / 3^{\text {rd }}$ distance of feeder beginning. The DVR fixes the voltage of its downstream side to a desired value of 0.98 pu by adding a small amount of voltage in series with the LV feeder. In this method, the $F_{I}$ reduces to zero in both modes. The numerical results are given in Table VII and prove the efficacy of the discussed improvement methods.

Although the costs related to options (1)-(3) for upgrading the feeder conductors or installing low voltage pad mounted capacitors are quite available for different ratings, however as DSTATCOMs and DVRs are not commonly used by utilities in distribution networks, therefore they are not available in large quantities in market in different ratings and their costs can vary depending on the manufacturer and time of order. Therefore, an economic feasibility analysis is not carried out for the discussed improvement methods.

\section{CONCLUSIONS}

In this paper, VU sensitivity and stochastic analyses were carried out to investigate the effects of PEVs' G2V and V2G operation modes and their connection points on VU of a LV residential feeder supplying the PEVs. Through the studies, it was demonstrated that PEVs have minor effect on VU at the beginning of the feeder. However, it was shown that VU might increase at the end of the feeder to more than the standard limit if PEVs, connected to low load phase of the system, are operating in V2G mode especially when they are located at feeder end nodes or when they have higher discharge capacities. Similar results are expected for PEVs when connected to a highly loaded phase and operating in G2V mode with higher charging levels. The failure index, which demonstrates the probability of non-standard VU in the network defined through the stochastic analysis, can increase up to $36.5 \%$ depending on the residential load demand and the operation mode, penetration level and connection points of PEVs. The failure index was found to be relatively large when majority of PEVs are located at feeder far end nodes (i.e. $54.6 \%$ in V2G mode and $32 \%$ in $\mathrm{G} 2 \mathrm{~V}$ mode) compared to when majority of PEVs are located at feeder beginning nodes (i.e. 5.5\% in V2G mode and $12.2 \%$ in G2V mode). In addition, it was shown that as PEVs penetration level increases from 10 to $50 \%$ in the 
network, the failure index increases (from 15.9 to $28 \%$ in $\mathrm{V} 2 \mathrm{G}$ mode and from 27.1 to $36.5 \%$ in $\mathrm{G} 2 \mathrm{~V}$ mode). The developed stochastic analysis tool was later utilised to verify the efficacy of VU reduction improvement methods such as installation of DSATCTOM or DVR, upgrading feeder cross section and installation of pad mounted switched capacitors and it was seen that the failure index can be reduced effectively when applying the discussed improvement methods.

\section{APPENDIX}

The technical data of the network under consideration in Section IV is given in Table VIII.

\section{REFERENCES}

[1] Alternate route: electrifying the transportation sector, Technical report, New York ISO, 2009.

[2] R.C. Green II, L. Wang and M. Alam, "The Impact of Plug-in Hybrid Electric Vehicles on Distribution Networks: A Review and Outlook," Elsevier Renewable and Sustainable Energy Reviews, Vol. 15, pp. 544-553, 2011.

[3] K.C. Nyns, E. Haesen and J. Driesen, "The impact of Vehicle-to-grid on the Distribution Grid," Electric Power Systems Research, Vol. 81, Issue 1, pp. 185-192, 2011.

[4] L.P. Fernández, T.G.S. Román, R. Cossent, C.M. Domingo and P. Frías, "Assessment of the Impact of Plug-in Electric Vehicles on Distribution Networks," IEEE Trans. on Power Systems, Vol. 26, No. 1, pp. 206-213, 2011.

[5] K.C. Nyns, E. Haesen and J. Driesen, “The Impact of Charging Plug-In Hybrid Electric Vehicles on a Residential Distribution Grid," IEEE Trans. on Power Systems, Vol. 25, No. 1, pp. 371-380, 2010.

[6] S. Acha, T.C. Green and N. Shah, "Effects of Optimised Plug-in Hybrid Vehicle Charging Strategies on Electric Distribution Network Losses," in Proc. of IEEE Transmission and Distribution Conference, pp. 1-6, 2010.

[7] A.S. Masoum, S. Deilami, P.S. Moses and A. Abu-Siada, "Impacts of Battery Charging Rates of Plug-in Electric Vehicle on Smart Grid Distribution Systems," in Proc. of IEEE PES Innovative Smart Grid Technologies Conference Europe (ISGT Europe), pp. 1-6, 2010. 
[8] J. Taylor, A. Maitra, M. Alexander, D. Brooks and M. Duvall, "Evaluation of the Impact of Plugin Electric Vehicle Loading on Distribution System Operations,” in Proc. of IEEE PES General Meeting, pp. 1-6, 2009.

[9] P.S. Moses, S. Deilami, A.S. Masoum and M.A.S. Masoum, "Power Quality of Smart Grids with Plug in Electric Vehicles Considering Battery Charging Profile," in Proc. of IEEE PES Innovative Smart Grid Technologies Conference Europe (ISGT Europe), pp. 1-7, 2010.

[10] M. Singh, I. Kar and P. Kumar, "Influence of EV on Grid Power Quality and Optimizing the Charging Schedule to Mitigate Voltage Imbalance and Reduce Power Loss," in Proc. of IEEE $14^{\text {th }}$ International Power Electronics and Motion Control Conf. (EPE/PEMC), pp.196-203, 2010.

[11] G.A. Putrus, P. Suwanapingkarl, D. Johnston, E.C. Bentley and M. Narayana, "Impact of Electric Vehicles on Power Distribution Networks," in Proc. of IEEE Vehicle Power and Propulsion Conf. (VPPC), pp. 827-831, 2009.

[12] M. Moghbel, M.A.S. Masoum, F. Shahnia and P. Moses, "Distribution Transformer Loading in Unbalanced Three-phase Residential Networks with Random Charging of Plug-in Electric Vehicles," in Proc. of Australian Universities Power Engineering Conf. (AUPEC), 2012.

[13] T.A. Short, Electric Power Distribution Handbook, CRC Press, 2004.

[14] P. Glasserman, Monte Carlo Methods in Financial Engineering, Springer, 2003.

[15] S. Asmussen and P.W. Glynn, Stochastic Simulation: Algorithms and Analysis, Springer, 2007.

[16] M.T. Bina, A. Kashefi, "Three-phase unbalance of distribution systems: Complementary analysis and experimental case study," International Journal of Electrical Power and Energy Systems, Vol. 33, Issue 4, pp. 817-826, May 2011.

[17] P. Pillay and M. Manyage, "Definitions of voltage unbalance," IEEE Power Engineering Review, pp. 50-51, May 2001.

[18] M.H.J. Bollen, “Definitions of voltage unbalance,” IEEE Power Engineering Review, pp. 52-53, May 2001.

[19] IEEE Recommended Practice for Monitoring Electric Power Quality, IEEE Standard 1159-1995.

[20] Planning Limits for Voltage Unbalance in United Kingdom, Engineering Recommendation P29, Electricity Association, Engineering and Safety Publications, 1990. 
[21] B. Das, "Consideration of input parameter uncertainties in load flow solution of three-phase unbalanced radial distribution system," IEEE Trans. on Power Systems, Vol. 21, No. 3, pp. 1088 1095, Aug. 2006.

[22] H.E. Farag, E.F. E. Saadany, R.E. Shatshat and A. Zidan, “A generalized power flow analysis for distribution systems with high penetration of distributed generation," Electric Power Systems Research, Vol. 81, Issue 7, pp. 1499-1506, July 2011.

[23] F. Shahnia, M.T. Wishart, A. Ghosh, G. Ledwich and F. Zare, "Smart demand side management of low-voltage distribution networks using multi-objective decision making," IET Generation, Transmission \& Distribution, Vol. 6, No. 10, pp. 968-1000, Oct. 2012.

[24] S. Deilami, A.S. Masoum, P.S. Moses and M.A.S. Masoum, "Real-Time Coordination of PlugIn Electric Vehicle Charging in Smart Grids to Minimize Power Losses and Improve Voltage Profile,” IEEE Trans. on Smart Grid, Vol. 2, No. 3, pp.456,467, Sept. 2011.

[25] M. Moghbel, Decentralised Coordinated Charging of Plug-In Electric Vehicles in Unbalanced Residential Networks to Control Distribution Transformer Loading, Voltage Profile and Current Unbalance”, Thesis, Curtin University.

[26] F. Shahnia, A. Ghosh, G. Ledwich and F. Zare, "Voltage Unbalance Reduction in Low Voltage Distribution Networks with Rooftop PVs," in Proc. of Australian Universities Power Engineering Conf. (AUPEC), pp. 1-5, 2010.

[27] F. Shahnia, A. Ghosh, G. Ledwich and F. Zare, "Voltage Correction in Low Voltage Distribution Networks with Rooftop PVs using Custom Power Devices," in Proc. of $37^{\text {th }}$ Annual Conf. on IEEE Industrial Electronics Society (IECON), pp. 991-996, 2011.

[28] A. Ghosh and G. Ledwich, Power Quality Enhancement using Custom Power Devices, Kluwer Academic Publishers, 2002. 


\section{LIST OF TABLES}

Table I. VU Values of Several Cases with Total Power Injection of $10 \mathrm{~kW}$ and $20 \mathrm{~kW}$ by PEVs in V2G Mode.

Table II. VU Values of Several Cases with Total Power Consumption of 100 A by PEVs in G2V Mode.

Table III. Stochastic Analysis Based $\lambda$ and FI of VU in the Studied LV Distribution Network for Different PEV Penetration Levels

Table IV. Stochastic Analysis Based $\lambda$ and FI of VU in the Studied LV Distribution Network for Different Residential Load Levels

Table V. Stochastic Analysis Based $\lambda$ and FI of VU in the Studied Network with Majority of PEVs Connected to Beginning, Middle and End of the Feeder

Table VI. Stochastic Analysis Based $\lambda$ and FI of VU in the Studied Network with Normal Distributions of PEV Charging and Discharging Capacities

Table VII. Stochastic Analysis Based $\lambda$ and FI of VU in the Studied LV Distribution Network for Five Improvement Methods

Table VIII. Technical Parameters of the Studied LV Distribution Network 


\section{LIST OF FIGURES}

Fig. 1 (a) Single line diagram of one phase of the studied LV distribution feeder,

(b) Schematic diagram of PEV in G2V mode,

(c) Schematic diagram of PEV in V2G mode.

Fig. 2 Monte Carlo flowchart for stochastic evaluation.

Fig. 3 (a) Variation of phase A voltage profile versus the location and charging level of the PEV,runningin G2V mode, connected to phase A,

(b) VU sensitivity analysis versus one PEV location and charging level, running in G2V mode, when connected to low load phase A,

(c) VU sensitivity analysis versus one PEV location and output power, running in V2G mode, when connected to low load phase A.

Fig. 4 VU at the beginning and end of Feeder-1 when PEVs are connected to different locations in all three feeders for:

(a) different constant output powers in V2G mode when connected to phase A,

(b) different charging levels in G2V mode when connected to phase A,

(c) different constant output powers in V2G mode when connected to phase C,

(d) different charging levels in G2V mode when connected to phase C.

Fig. 5 (a) Monte Carlo results of VU for PEVs in G2V mode for $\mathrm{N}=10,000$ trials for penetration level of $30 \%$,

(b) Probability density function of VU for PEVs in G2V mode for penetration level of $30 \%$. 
Table I. VU Values of Several Cases with Total Power Injection of $10 \mathrm{~kW}$ and $20 \mathrm{~kW}$ by PEVs in V2G

Mode.

\begin{tabular}{|c|c|c|c|c|c|}
\hline \multicolumn{2}{|r|}{ PEV connected to } & \multicolumn{2}{|c|}{ Low Load Phase } & \multicolumn{2}{|c|}{ Highly Loaded Phase } \\
\hline $\begin{array}{l}\text { Total PEV Power } \\
\text { Injection into Grid }\end{array}$ & PEV No $\times$ Output Power & $\begin{array}{c}\text { Feeder } \\
\text { beginning }\end{array}$ & $\begin{array}{l}\text { Feeder } \\
\text { End }\end{array}$ & $\begin{array}{c}\text { Feeder } \\
\text { beginning }\end{array}$ & $\begin{array}{c}\text { Feeder } \\
\text { End }\end{array}$ \\
\hline \multirow{7}{*}{$10 \mathrm{~kW}$} & $2 \times 5 \mathrm{~kW}$ & 0.91 & 1.97 & 0.86 & 1.73 \\
\hline & $2 \times 5 \mathrm{~kW}$ & 0.92 & 2.03 & 0.85 & 1.69 \\
\hline & $2 \times 5 \mathrm{~kW}$ & 0.92 & 2.03 & 0.85 & 1.69 \\
\hline & $5 \times 2 \mathrm{~kW}$ & 0.94 & 2.13 & 0.84 & 1.60 \\
\hline & $5 \times 2 \mathrm{~kW}$ & 0.93 & 2.11 & 0.84 & 1.61 \\
\hline & $5 \times 2 \mathrm{~kW}$ & 0.95 & 2.17 & 0.84 & 1.56 \\
\hline & $10 \times 1 \mathrm{~kW}$ & 0.91 & 1.97 & 0.86 & 1.72 \\
\hline \multirow{8}{*}{$20 \mathrm{~kW}$} & $4 \times 5 \mathrm{~kW}$ & 0.96 & 2.12 & 0.83 & 1.62 \\
\hline & $4 \times 5 \mathrm{~kW}$ & 0.99 & 2.33 & 0.81 & 1.46 \\
\hline & $4 \times 5 \mathrm{~kW}$ & 1.01 & 2.42 & 0.80 & 1.41 \\
\hline & $5 \times 4 \mathrm{~kW}$ & 1.00 & 2.37 & 0.81 & 1.43 \\
\hline & $5 \times 4 \mathrm{~kW}$ & 0.99 & 2.30 & 0.81 & 1.48 \\
\hline & $5 \times 4 \mathrm{~kW}$ & 0.99 & 2.30 & 0.81 & 1.48 \\
\hline & $10 \times 2 \mathrm{~kW}$ & 0.94 & 2.10 & 0.84 & 1.61 \\
\hline & $20 \times 1 \mathrm{~kW}$ & 0.90 & 1.95 & 0.85 & 1.70 \\
\hline
\end{tabular}

Table II. VU Values of Several Cases with Total Power Consumption of 100 A by PEVs in G2V Mode.

\begin{tabular}{|c|c|c|c|c|c|}
\hline \multicolumn{2}{|r|}{ PEV connected to } & \multicolumn{2}{|c|}{ Low Load Phase } & \multicolumn{2}{|c|}{ Highly Loaded Phase } \\
\hline $\begin{array}{l}\text { Total PEV Power } \\
\text { Consumption }\end{array}$ & PEV No $\times$ Charging level & $\begin{array}{c}\text { Feeder } \\
\text { beginning }\end{array}$ & $\begin{array}{l}\text { Feeder } \\
\text { End }\end{array}$ & $\begin{array}{c}\text { Feeder } \\
\text { beginning }\end{array}$ & $\begin{array}{c}\text { Feeder } \\
\text { End }\end{array}$ \\
\hline $100 \mathrm{~A}$ & $\begin{array}{l}10 \times 10 \mathrm{~A} \\
5 \times 20 \mathrm{~A} \\
5 \times 20 \mathrm{~A} \\
5 \times 20 \mathrm{~A}\end{array}$ & $\begin{array}{l}0.79 \\
0.74 \\
0.70 \\
0.70\end{array}$ & $\begin{array}{l}1.56 \\
1.48 \\
1.45 \\
1.45\end{array}$ & $\begin{array}{l}0.87 \\
0.87 \\
0.87 \\
0.87\end{array}$ & $\begin{array}{l}1.71 \\
1.72 \\
1.75 \\
1.75\end{array}$ \\
\hline
\end{tabular}


Table III. Stochastic Analysis Based $\lambda$ and $F_{I}$ of VU in the Studied LV Distribution Network for Different PEV Penetration Levels

\begin{tabular}{l|c|c|c|c|c|c|c|}
\hline PEV Penetration Level [\%] & 0 & \multicolumn{2}{|c|}{10} & \multicolumn{2}{|c|}{30} & \multicolumn{2}{c|}{50} \\
\hline PEV Operation Mode & & G2V & V2G & G2V & V2G & G2V & V2G \\
\hline$\lambda$ at the beginning of the feeder & 0.88 & 0.96 & 0.96 & 0.95 & 0.96 & 0.95 & 0.96 \\
$\lambda$ at the end of the feeder & 1.84 & 1.90 & 1.90 & 1.89 & 1.89 & 1.89 & 1.89 \\
Failure Index $\left(F_{I} \%\right)$ & - & 27.1 & 15.9 & 34.1 & 26.0 & 36.5 & 28.0 \\
\hline
\end{tabular}

Table IV. Stochastic Analysis Based $\lambda$ and $F_{I}$ of VU in the Studied LV Distribution Network for Different Residential Load Levels

\begin{tabular}{l|c|c|c|c|c|c}
\hline Residential Load Status & \multicolumn{2}{|c|}{ Highly Unbalanced } & \multicolumn{2}{|l|}{ Lightly Unbalanced } & \multicolumn{2}{c}{ Almost Balanced } \\
\hline PEV Operation Mode & G2V & V2G & G2V & V2G & G2V & V2G \\
\hline$\lambda$ at the beginning of the feeder & 1.03 & 1.02 & 0.90 & 0.90 & 0.72 & 0.72 \\
$\lambda$ at the end of the feeder & 2.03 & 2.00 & 1.79 & 1.77 & 1.43 & 1.43 \\
Failure Index $\left(F_{I} \%\right)$ & 64.3 & 67.0 & 25.3 & 11.8 & 3.8 & 0.70 \\
\hline
\end{tabular}

Table V. Stochastic Analysis Based $\lambda$ and $F_{I}$ of VU in the Studied Network with Majority of PEVs Connected to Beginning, Middle and End of the Feeder

\begin{tabular}{l|c|c|c|c|c|c}
\hline Majority of PEVs installed at & \multicolumn{2}{|c|}{ Beginning of Feeder } & \multicolumn{2}{|c}{ Middle of Feeder } & \multicolumn{2}{|c}{ End of Feeder } \\
\hline PEV Operation Mode & G2V & V2G & G2V & V2G & G2V & V2G \\
\hline$\lambda$ at the beginning of the feeder & 0.96 & 0.97 & 0.96 & 0.97 & 0.95 & 0.97 \\
$\lambda$ at the end of the feeder & 1.89 & 1.91 & 1.89 & 1.93 & 1.89 & 1.97 \\
Failure Index $\left(F_{I} \%\right)$ & 12.2 & 5.5 & 23.0 & 28.6 & 32.0 & 54.6 \\
\hline
\end{tabular}


Table VI. Stochastic Analysis Based $\lambda$ and $F_{I}$ of VU in the Studied Network with Normal Distributions of PEV Charging and Discharging Capacities

\begin{tabular}{l|c|c|c|c|c|c|c|c}
\hline Charge/discharge capacity of PEVs & \multicolumn{3}{|c|}{ G2V } & \multicolumn{5}{c}{ V2G } \\
\hline PEV Operation Mode & $10 \mathrm{~A}$ & $15 \mathrm{~A}$ & $20 \mathrm{~A}$ & $1 \mathrm{~kW}$ & $2 \mathrm{~kW}$ & $3 \mathrm{~kW}$ & $4 \mathrm{~kW}$ & $5 \mathrm{~kW}$ \\
& & & & & & & & \\
\hline & 0.95 & 0.95 & 0.95 & 0.96 & 0.96 & 0.96 & 0.96 & 0.96 \\
at the beginning of the feeder & 1.88 & 1.89 & 1.89 & 1.89 & 1.89 & 1.89 & 1.89 & 1.89 \\
at the end of the feeder & 31.3 & 35.3 & 38.3 & 14.9 & 20.6 & 25.1 & 28.6 & 30.1 \\
Failure Index $\left(F_{I} \%\right)$ & & & & & & & \\
\hline
\end{tabular}

Table VII. Stochastic Analysis Based $\lambda$ and $F_{I}$ of VU in the Studied LV Distribution Network for Five Improvement Methods

\begin{tabular}{|c|c|c|c|c|c|c|c|c|c|c|c|c|}
\hline \multirow[b]{2}{*}{ PEV Operation Mode } & \multicolumn{2}{|c|}{$\begin{array}{c}\text { Nominal } \\
\text { Case }\end{array}$} & \multicolumn{2}{|c|}{ Method-1 } & \multicolumn{2}{|c|}{ Method-2 } & \multicolumn{2}{|c|}{ Method-3 } & \multicolumn{2}{|c|}{ Method-4 } & \multicolumn{2}{|c|}{ Method-5 } \\
\hline & G2V & V2G & $\mathrm{G} 2 \mathrm{~V}$ & V2G & $\mathrm{G} 2 \mathrm{~V}$ & V2G & G2V & V2G & $\mathrm{G} 2 \mathrm{~V}$ & V2G & $\mathrm{G} 2 \mathrm{~V}$ & V2G \\
\hline $\begin{array}{l}\lambda \text { at the beginning of } \\
\text { the feeder }\end{array}$ & 0.95 & 0.96 & 0.95 & 0.96 & 0.75 & 0.75 & 0.75 & 0.75 & 0.73 & 0.66 & 0.96 & 0.96 \\
\hline $\begin{array}{l}\lambda \text { at the end of the } \\
\text { feeder }\end{array}$ & 1.89 & 1.89 & 1.73 & 1.73 & 1.48 & 1.48 & 1.35 & 1.36 & 0.73 & 0.59 & 0.95 & 0.96 \\
\hline Failure Index $\left(F_{I} \%\right)$ & 34.1 & 26.0 & 7.7 & 0.5 & 0.4 & 0 & 0 & 0 & 0 & 0 & 0 & 0 \\
\hline
\end{tabular}

Table VIII. Technical Parameters of the Studied LV Distribution Network

\begin{tabular}{ll}
\hline Transformer & $11 \mathrm{kV} / 400 \mathrm{~V}, 400 \mathrm{kVA}, \Delta / \mathrm{Y}_{\text {grounded }}, Z_{I}=4 \%$ \\
Feeders & $3 \times 70+35 \mathrm{~mm}^{2} \mathrm{AAC}, 400 \mathrm{~m}$ overhead line for $\mathrm{LV}$ feeder \\
& $3 \times 50 \mathrm{~mm}^{2}$ ACSR, $2 \mathrm{~km}$ overhead line for MV feeder \\
& $1-5 \mathrm{~kW}$, unity power factor, $L=5 \mathrm{mH}$ in V2G mode \\
PEVs & 10,15 and 20 A constant current load in $\mathrm{G} 2 \mathrm{~V}$ mode \\
& $1 \mathrm{~kW}, \cos \varphi=0.95, z=51.9840+\mathrm{j} \times 17.0863 \Omega$ \\
& $2 \mathrm{~kW}, \cos \varphi=0.95, z=25.9920+\mathrm{j} \times 8.5432 \Omega$ \\
& $3 \mathrm{~kW}, \cos \varphi=0.95, z=17.3280+\mathrm{j} \times 5.6954 \Omega$ \\
\hline
\end{tabular}




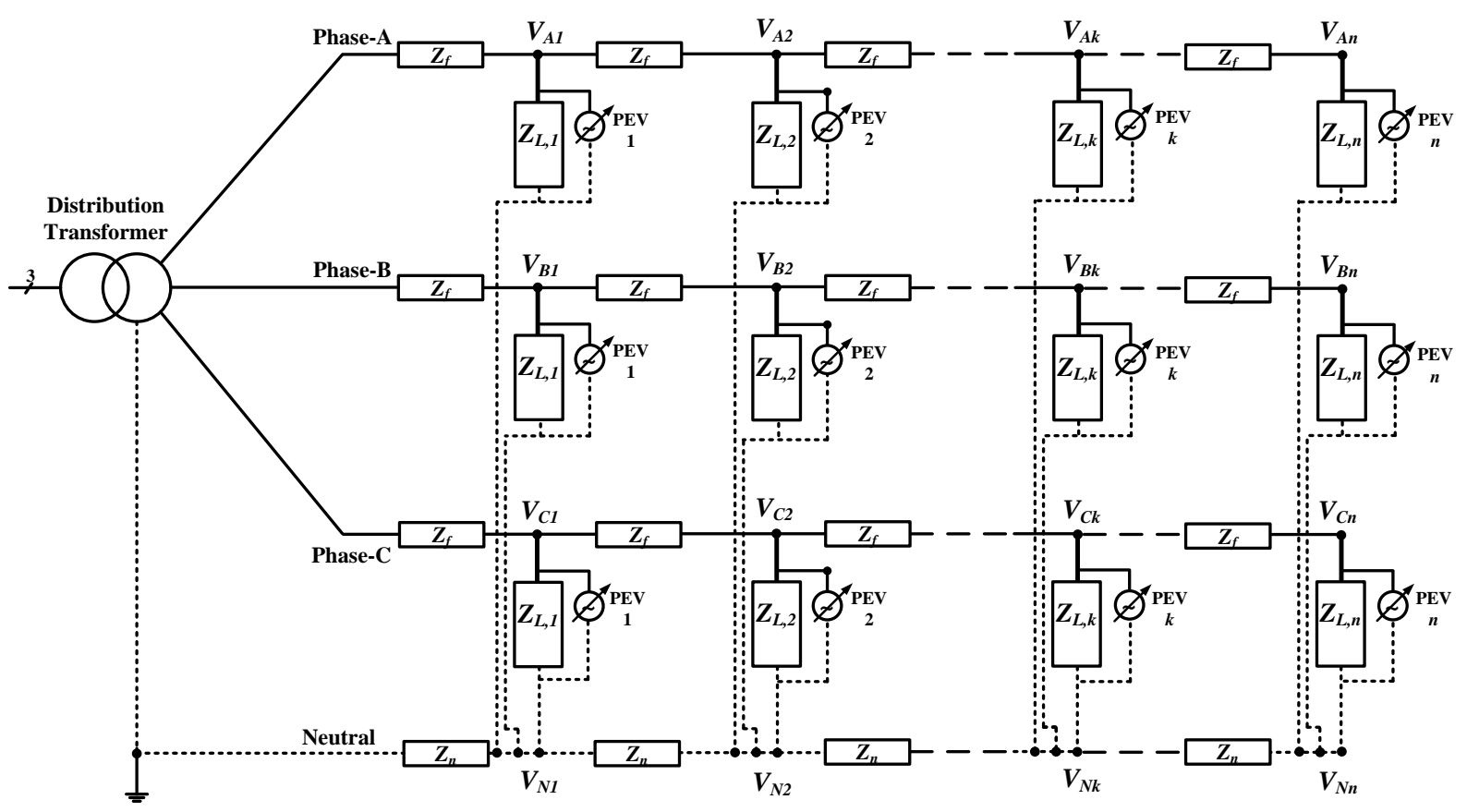

(a)

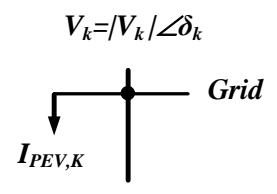

(b)

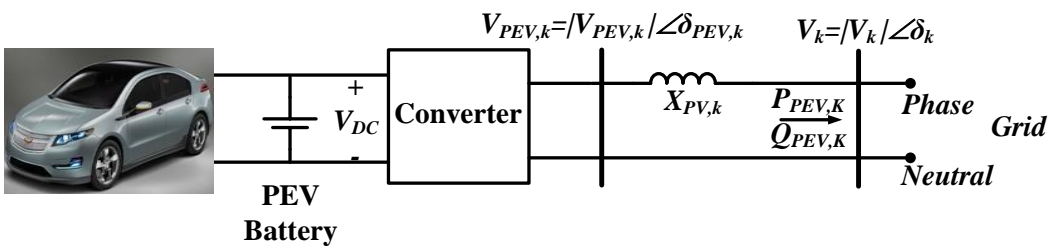

(c)

Fig. 1 (a) Single line diagram of one phase of the studied LV distribution feeder, (b) Schematic diagram of PEV in G2V mode, (c) Schematic diagram of PEV in V2G mode. 


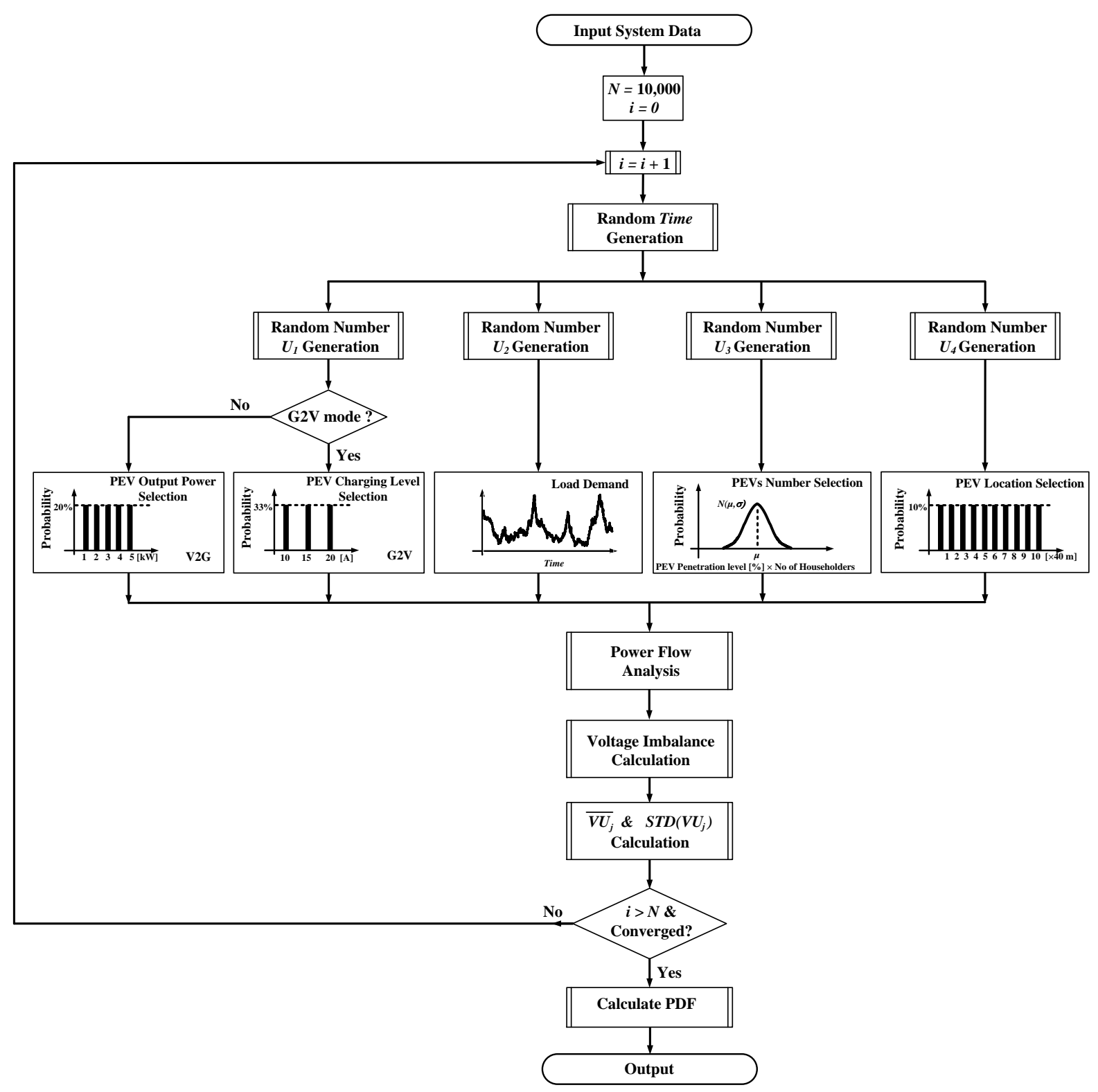

Fig. 2. Monte Carlo flowchart for stochastic evaluation. 


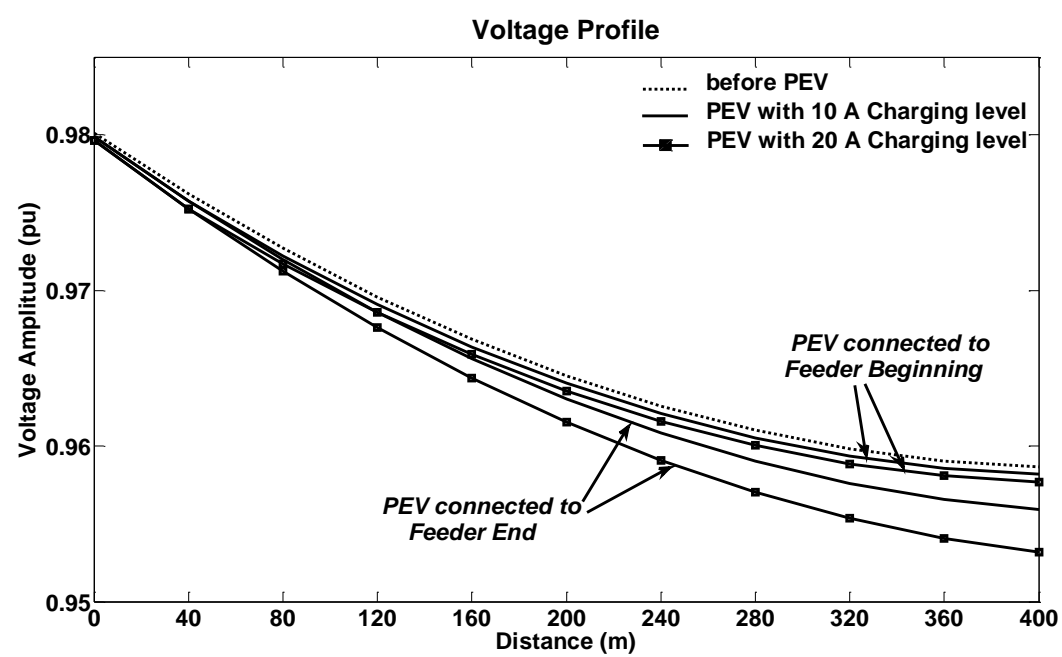

(a)

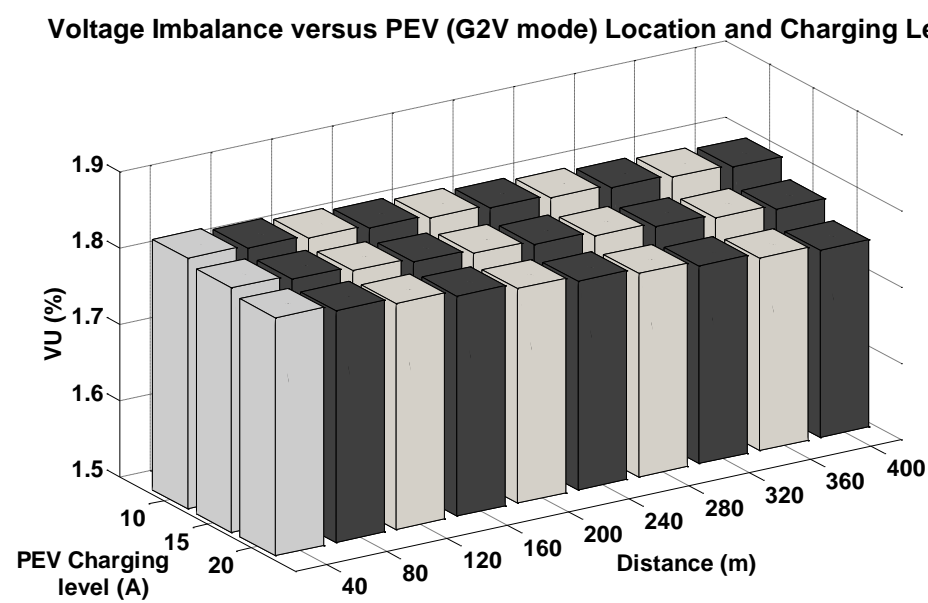

(b)

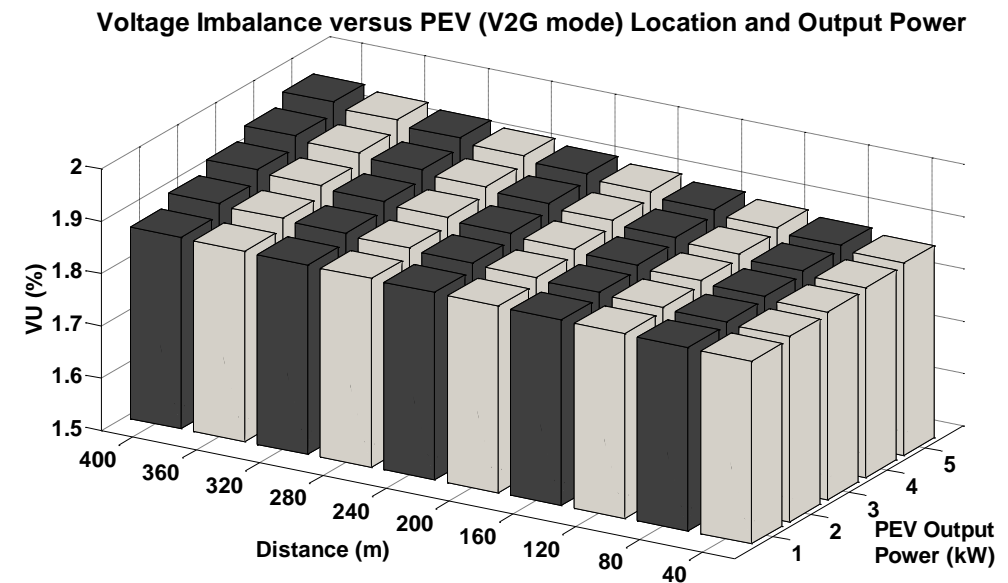

(c)

Fig. 3 (a) Variation of phase $A$ voltage profile versus the location and charging level of the PEV,runningin G2V mode, connected to phase $A$, (b) VU sensitivity analysis versus one PEV location and charging level, running in G2V mode, when connected to low load phase $A$, (c) VU sensitivity analysis versus one PEV location and output power, running in V2G mode, when connected to low load phase $A$. 


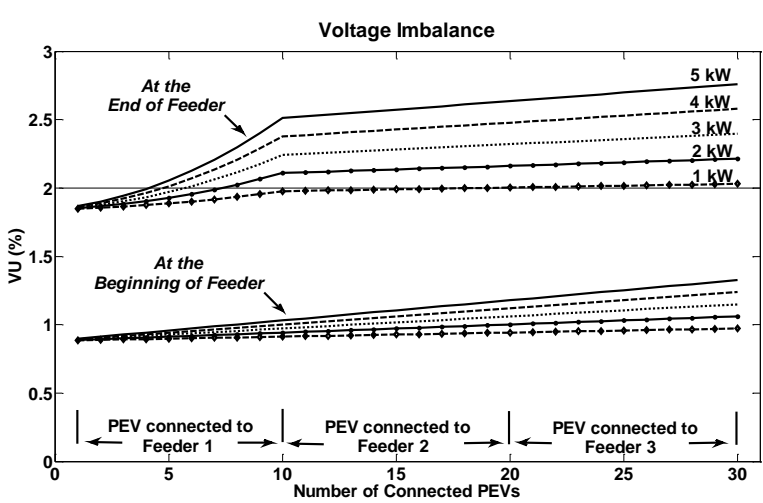

(a)

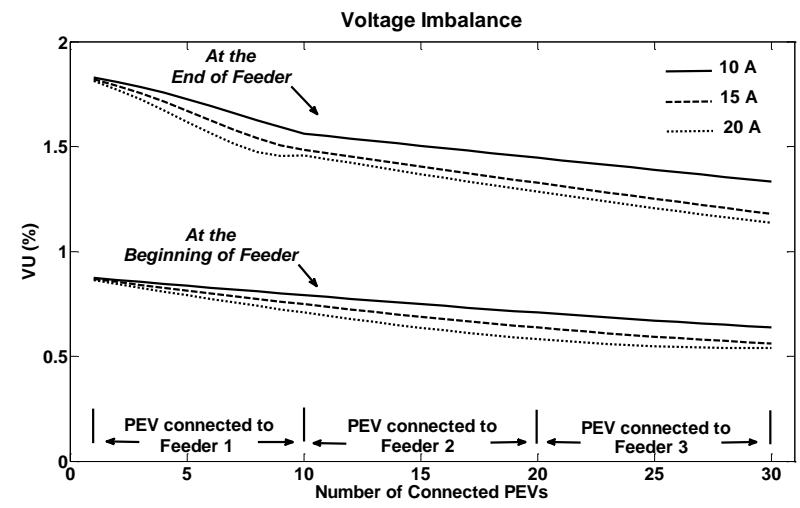

(b)

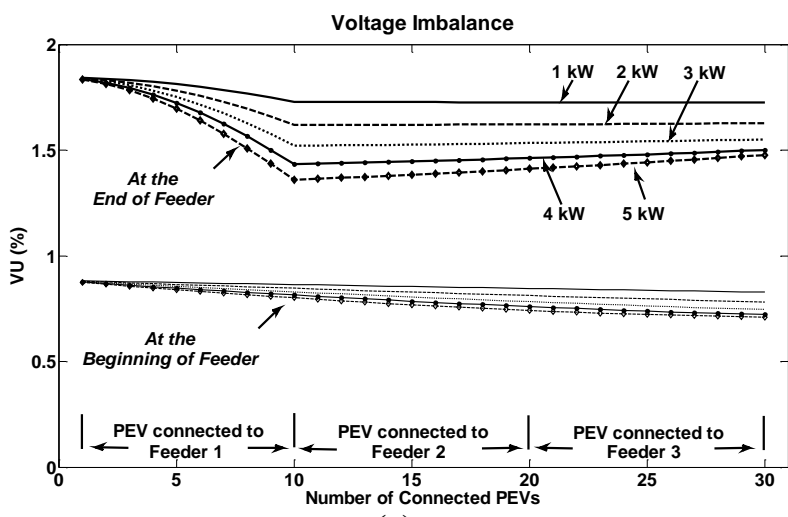

(c)

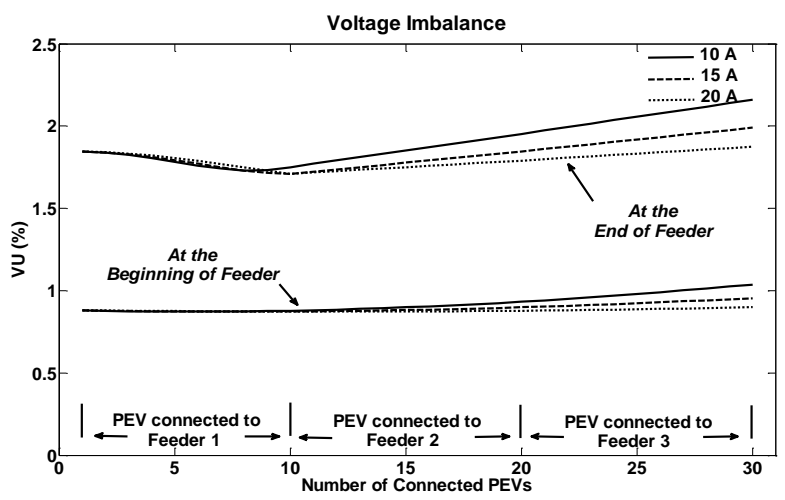

(d)

Fig. $4 \mathrm{VU}$ at the beginning and end of Feeder-1 when PEVs are connected to different locations in all three feeders for (a) different constant output powers in V2G mode when connected to phase $A$, (b) different charging levels in G2V mode when connected to phase $A$, (c) different constant output powers in V2G mode when connected to phase $C$, (d) different charging levels in G2V mode when connected to phase $C$.

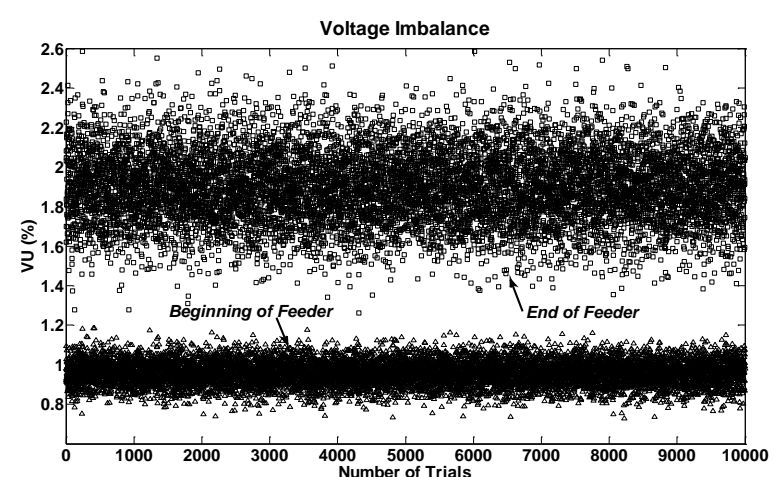

(a)

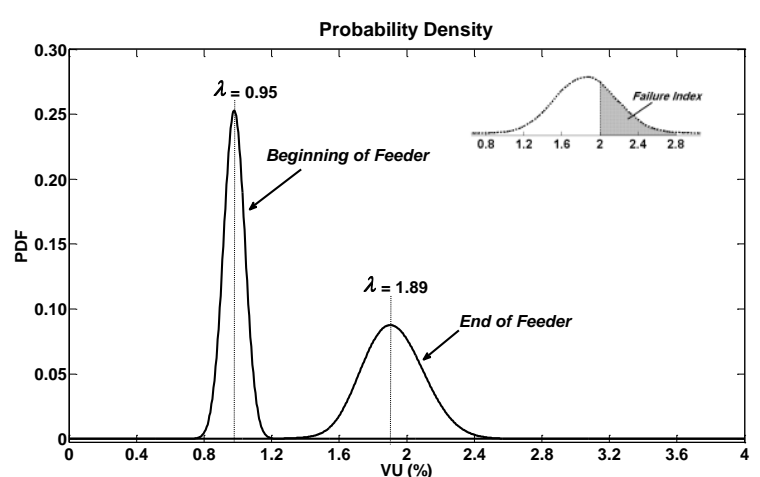

(b)

Fig. 5 (a) Monte Carlo results of VU for PEVs in G2V mode for $\mathrm{N}=10,000$ trials for penetration level of $30 \%$, (b) Probability density function of VU for PEVs in G2V mode for penetration level of $30 \%$. 